\section{EMBRYRIDDLE \\ Aeronautical University}

SCHOLARLY COMMONS
International Journal of Aviation, Aeronautics, and Aerospace

\title{
Big Five Technologies in Aeronautical Engineering Education: Scoping Review
}

Ruth Martinez-Lopez

Samara National Research University (Russia); Sevilla University (Spain), rm@ssau.ru

Follow this and additional works at: https://commons.erau.edu/ijaaa

Part of the Aviation and Space Education Commons, Computer and Systems Architecture Commons, Curriculum and Instruction Commons, Data Storage Systems Commons, Digital Communications and Networking Commons, Educational Assessment, Evaluation, and Research Commons, Educational Technology Commons, Engineering Education Commons, Other Aerospace Engineering Commons, and the Robotics Commons

\section{Scholarly Commons Citation}

Martinez-Lopez, R. (2019). Big Five Technologies in Aeronautical Engineering Education: Scoping Review. International Journal of Aviation, Aeronautics, and Aerospace, 6(3). https://doi.org/10.15394/ ijaaa.2019.1342

This Literature Review is brought to you for free and open access by the Journals at Scholarly Commons. It has been accepted for inclusion in International Journal of Aviation, Aeronautics, and Aerospace by an authorized administrator of Scholarly Commons. For more information, please contact commons@erau.edu. 


\section{Big Five Technologies in Aeronautical Engineering Education: Scoping Review}

\section{Cover Page Footnote}

This work was supported by the Ministry of Education and Science of the Russian Federation and the Russian Academic Excellence Project '5-100'. Many thanks to Professor Valeriy Dmitrievich Elenev, Director of the Institute of Aviation Technology at Samara National Research University (Russia), special thankfulness to professors and researchers of the Institute for their support to this study. Thanks to Pilar Gálvez Corral, a student of the master's degree in the field of ICT for language education and processing of the UNED (National University of Distance Education. Spain), for her collaboration in the classification of the dataset in the Big Five technologies. 


\section{Introduction}

The widespread use of digital technologies demands more reviews in domain-specific areas to provide empirical evidence on its pedagogical use and outcomes. Technological complexity has been increasing exponentially in the aerospace industry since its inception (Guffarth \& Barber, 2017). Different areas of aerospace engineering, including avionics, are being influenced by augmented and virtual reality (AR/VR), the Internet of Things (IoT), Artificial Intelligence, and 3D printing (Infosys, 2017). Several reports indicate the increasing trends towards mobile-learning, cloud computing, and the IoT among others (Durak, 2018; Vagdevi \& Guruprasad, 2016). Accordingly, the International Paris Air Show of 2017 highlighted the growing importance of digital technologies in aeronautical production (Janichewski, 2017).

Digitalization is a broad term related to new technologies such as 3D printing, augmented reality systems, robotics, Big Data, autonomous systems, cloud computing, IoT, among others (Bruno, 2016). Concerning this, mobile technology, cloud computing, Big data, social media, and IoT has been identified as the Big Five technologies (Hinchcliffe, 2011; Spil, Pris, \& Kijl, 2017). A series of recent studies highlighted that the industry is already using digital technologies to support the human workforce of the maintenance engineers specializing in aircraft engines (World Economic Forum, 2017). This increase in the use of digital technologies, such as the IoT, is forcing the evolution in the production processes of the maintenance of the aeronautical industry (Altran, 2018). Likewise, a recent study concluded that the capability development for digital technologies is one of the key trends driving the aerospace engineering services market (Infosys, 2017).

These indicators translate into an increasing use of technology-based tools in classroom teaching, as reported by prospective sectorial studies (Salgado, Belderrain, \& Devezas, 2018). Consequently, technological changes continually create new demands on both engineers and the educational system that produces them. The competition for more digital science and engineering talent from growth industries is high and, it is expected to grow more from new and different sources (Schmidt, n.d.). Although technology is recognized as being relevant in engineering studies (Igual, Plaza, Marcuello, \& Arcega, 2018), there is research claiming that the academic curricula require significant changes to adjust to the technology that is part of the aerospace system, such as a fast adoption (Long, 2015), Furthermore, previous research emphasizes that aerospace engineering education needs to address emergent learning and knowledge technologies, with practical application in the field (Noor, 2011). It has been suggested that aerospace engineering, one of the major R\&D fields indicated in the analysis of the Scientometrics and Technology mining agenda (Efimenko, Khoroshevsky, \& Noyons, 2016), not only depends on technology implementation, but also on the utilization of digital technologies by the teachers and the students. 
A recent review (Van Der Heiden, Pohl, Bin Mansor, \& Van Genderen, 2015) recommended that researchers should have an in-depth knowledge of aerospace technology and that teachers, should be experienced in its integration in the curriculum, and be knowledgeable in the methods of transfering this technology.

Likewise, prior research suggested that teachers should stimulate students' creative skills while keeping the professional and practical base (Ahmed, 2014). Nevertheless, a recent study reclaimed more empirical evidence to assure that the use of digital technologies improves quality (Munro, 2018).

In this study, mobile technology, cloud computing, Big data, social media, and the IoT, identified as the Big Five technologies (Hinchcliffe, 2011; Spil et al., 2017), will be selected to offer an overview about the use of digital technology in aerospace engineering and the outcomes in education. Despite recent research focusing on the study of space technology trends (Pelicioni, Ribeiro, Devezas, Belderrain, \& Melo, 2018), the development of space propulsion engines technology over the last 50 years (Salgado et al., 2018), and the absorption of aerospace technology through exploration of key aspects of education (Van Der Heiden et al., 2015), studies on the Big Five technologies used in the aeronautical engineering field remain unexplored.

Furthermore, taking into account that the most important focus on utilizing technology is to emphasize pedagogy and practices that support and enhance teaching and learning (Hamilton, Rosenberg, \& Akcaoglu, 2016), the type of evidence will be explored through the Design-Based Research (DBR) methodology (Wang \& Hannafin, 2005). How these Big Five digital technologies influence teaching and learning of aeronautical engineering is a relevant question to identify and promote empirical research. The exploration of the digital technology pedagogical use can allow the identification of what has been effectively implemented in education, what will require improvement and what research gaps exist.

A scoping review will be helpful to get potential insights for implementing digital technologies and suggest possible directions for further research. In the knowledge of the author, this is the first scoping review focusing on the identification of current research regarding the use of digital technologies in aeronautical engineering.

A preliminary search for existing scoping reviews and systematic mapping studies on the use of digital technologies in aeronautical engineering conducted in Google Scholar, Scopus, Web of Science and OpenGrey, did not return any result on this topic. The lack of a comprehensive review that includes the digital technologies used in aeronautical engineering guides the research questions for this scoping review, which is "What Big Five technologies have been used in aeronautical engineering?" The research subquestion is "What design-based research interventions exist that used the Big Five technologies in aeronautical engineering education?" 
This study provides a scoping review on the use of the Big Five technologies in aeronautical engineering, identifying trending topics, possible gaps in the research and providing recommendations for the scientific community on future directions of research topics.

\section{Methodology}

The scoping review approach was chosen because the topic has not been reviewed comprehensively before (Arksey \& O'Malley, 2005). In accordance with the JBI methodology (Peters et al., 2015) and the PRISMA guidelines (Moher, Liberati, Tetzlaff, Altman \& Grp, 2009; Shamseer et al., 2015), the objectives, inclusion criteria and methods were specified in advance and documented in a protocol.

To identify the trending topics in the use of the Big Five Technologies and understand the conceptual structure in the aeronautical engineering research, social network analysis (SNA) methodology was undertaken (Wasserman \& Faust, 1994) in a three-stage approach for the sampling of articles. In the first stage, the conceptual structure of the field was explored with co-occurrence of keywords (Callon, Courtial \& Laville, 1991) established in 3 to have an overview of the evolution of the research topic. Then, topics were defined, classified and visualized by network and density with cluster analysis performed in 8 co-words to analyze its position and the dynamics of the whole research field. Furthermore, keyword analysis at the micro-level of the 8 co-words network was performed to obtain a complementary perspective. This approach allows an understanding of how the research field has been progressing relative to the use of the Big Five technologies.

In the third final stage, two reviewers categorized the articles by type of digital technology. Documents related to education were selected and coword analysis performed with a low (broad) and a higher threshold (focus). This approach allowed an interactional analysis by the examination of the different networks, from the general to the specifically related to education (Callon et al., 1991). Then, the articles related to education were categorized from a design-based research approach (Collins, Joseph, \& Bielaczyc, 2009; Wang \& Hannafin, 2005). Apart from this, the most cited papers in the whole dataset were identified and analyzed in the overall network. The study of the scientific and technological achievements in aeronautical engineering from this approach has not been analyzed in the research literature.

\section{Inclusion/Exclusion Criteria}

The inclusion and exclusion criteria were determined as the publication related to aerospace engineering, the purpose of the publication addressed digital technologies concerning aerospace engineering, published between 1970 and 2018 (request date May 2018), and in English. Finally, redundant publications were excluded. 


\section{Data Sources and Search Strategies}

Initially, the search string was used on the database Scopus and WoS Core Collection, as these two databases complement each other (Meho \& Yang, 2007). The Aerospace Research Central (ARC) database (AIAA Association Website, 2018) did not return any relevant results. The digital technologies were limited to mobile technology, cloud computing, Big data, social media and, Internet of things referenced as the Big Five technologies (Hinchcliffe, 2011; Spil et al., 2017). The Web 2.0 and social web keywords were used to delimit the term social media.

To take advantage of the combination of keywords, the term cloud computing was referenced as cloud to include broad references to cloud technologies. Table 1 includes the search string defined in the scoping review. The first search string (1) was used in Scopus and WoS with the purpose of generating a wide range of records to perform social network analysis about the use of the Big Five Technologies in aeronautical engineering. Papers related to education were selected for further analysis. The second search string (2) was related to terms that capture design-based research in education. This search was used in Scopus and WoS. Within the 2142 document results, a search was defined to identify the use of the Big Five Technologies (2.1). From the 83 results, only articles were selected for content analysis $(n=23)$.

Table 1

Search strategy in Scopus

\begin{tabular}{|c|c|}
\hline Field & Strategy \\
\hline TITLE-ABS-KEY (1) & To capture a wide range of records \\
\hline (title, abstract, author & ("digital technolog*" OR "emergent technolog*" \\
\hline \multirow[t]{2}{*}{ keyword and keyword plus) } & OR "mobile" OR "cloud" OR "big data" OR \\
\hline & $\begin{array}{l}\text { "Internet of things" OR IoT OR "social media" OR } \\
\text { "web 2.0" OR "social web") AND ("aerospace } \\
\text { engineering" OR "aeronautical engineering" OR } \\
\text { "aviation engineering") }\end{array}$ \\
\hline Document type (DOCTYPE) & $\begin{array}{l}\text { All (Conference paper, article, conference review, } \\
\text { review, short survey, editorial, note report) }\end{array}$ \\
\hline TITLE-ABS-KEY (2) & To identify Design-Based Research \\
\hline (title, abstract, author & (("aerospace engineering" OR "aeronautical \\
\hline keyword and keyword plus) & $\begin{array}{l}\text { engineering" OR "aviation engineering") AND } \\
\text { (teach* OR train* OR education)) }\end{array}$ \\
\hline \multirow[t]{4}{*}{ Search within results (2.1) } & "digital technolog*" OR "emergent technolog*" OR \\
\hline & "mobile" OR "cloud" OR "big data" OR "internet \\
\hline & of things" OR IoT OR "social media" OR "web 2.0" \\
\hline & OR "social web" \\
\hline Document type (DOCTYPE) & Article \\
\hline Publication year (PY) & All years \\
\hline Subject category (SC) & All \\
\hline
\end{tabular}

The title, abstracts and keywords were analyzed. To avoid bias, the first search 
string (1) included the conference proceedings (Paez, 2017) and the results (2 and 3) were qualitative interpreted (Gonzalez-Teruel, Gonzalez-Alcaide, Barrios, \& Abad-Garcia, 2015).

\section{Conceptual Structure}

With the data mining techniques (Cozzens et al., 2010) of co-word (Callon et al., 1991; Yan \& Ding, 2012) cluster analysis was performed to identify the digital technologies employed in the conceptual structure of the aeronautical engineering research within the dataset (Table 1.1). In the coword analysis with VOSViewer 1.6.5 (van Eck \& Waltman, 2017), all the keywords were selected (Colicchia, Creazza, \& Strozzi, 2017; Zhang et al., 2015).

Firstly, the co-word clusters were performed with co-occurrences established in 3, as the minimum. The map was explored by overlay visualization. The clusters were filtered for each digital technology in VOSviewer, to identify its location in the cluster or clusters and then, analyzed in the whole network. This approach was repeated with the number of cooccurrences established at a maximum of 8 . The results were compared and analyzed.

The 447 academic papers of the dataset were input into an excel spreadsheet to categorize the data concerning the type of digital technology used or "other", in the case of no coincidence. The evolution of the use of each digital technology in the academic papers was analyzed by the year of publication.

Then, the articles $(n=65)$ were examined taking into account the whole cluster where the digital technology was located in the co-word analysis established at a maximum of 8 co-occurrences and the most cited articles from the citation report in Scopus. In addition, the network characteristics of the coword matrix $(n=8)$ were analyzed at micro-level using SocNetV-2.3 mainly, to perform the betweenness centrality $(\mathrm{BC})$ and the eigenvector centrality (EV) measure (Zhang, Li, Liu, Chen, \& Chai, 2017).

Since the network was edge-weighted, edge weights were considered in BC, taken into account to compute distances and, inverted during calculations. Concerning Degree Centrality (DC), because the graph was weighted, Group Centralization could not be computed. Since this network was disconnected, the ordinary Closeness Centrality index (CC) was not defined. Instead, the Influence Range Closeness Centrality (IRCC) index, which considers how proximate is each node to the nodes in its influence range, was performed. The Gil and Schmidt Power Centrality (PC) index was used to enhance the BC results (Sinclair, 2009).

\section{Results and Discussions}

Out of 57 million records of Scopus, a dataset of 447 papers was extracted. After content analysis revision, documents no related to the criteria defined in the search string were excluded $(n=7) .440$ papers were selected for 
more in-depth analysis of categorization under the Big Five technologies used.

\section{The Conceptual Structure of Co-Word in 3}

The analysis of the overlay visualization (Figure 1) of keywords included in the 9 clusters of this highly centralized network in aerospace engineering indicates a clear evolution in three groups. An original group, in purple (2000-2002), at the left of the illustration, a second group, in green, at the bottom-center from the year 2002 to 2008 and, the last one, in yellow, between the top of the right corner and the top of the centre (2010-).

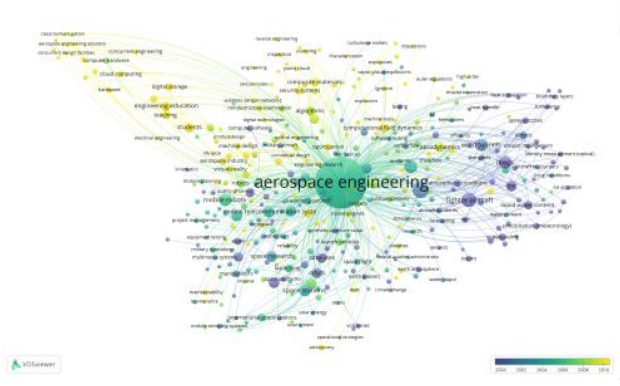

Figure 1. Overlay co-words (3).

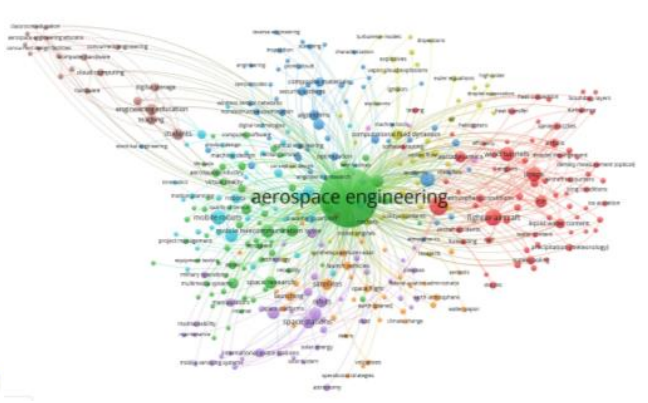

Figure 2. Network of co-words (3).

The network visualization (Figure 2) indicates that the original group (2000-2002) is mainly dominated by cluster 1 (70 items), which is characterized by a lack of the digital technologies covered in this study. The developments of NASA monopolize this cluster, the keyword aerodynamics is occupying a relevant position surrounded by wind tunnels, fighter aircraft, drops, ice, and liquid water content.

The second group at the center and the bottom-right corner, from the year 2002 to 2008 (Figure 1), is commanded by the cluster 2 (Figure 2) with 64 items, not only focused on aerospace engineering, satellite communication system, space research, and computing simulation but also, aircraft, aviation, and flight dynamics. This cluster is dominated by the military sector in aircraft, applications, communication and engineering. The research in this second group (Figure 1) includes the digital technologies of Big Data, Virtual Reality, the IoT, mobile computing and mobile telecommunications (Table 2). Also, the Artificial Intelligence and the Virtual Reality technologies are located here.

In fact, cluster 2 includes the keyword technology transfer. Cluster 2 is overlapped by cluster 5 ( 44 items), which is related to the space stations by one side and, by another, to spacecraft and orbits. These sub-groups are connected with cluster 1 via the keyword NASA and cluster 2 with the keyword aerospace engineering in the first sub-group and, space research in the second case. The digital technology of mobile servicing systems is located here (Table 2). Cluster 4 (45 items) in which the global system for mobiles 
(Table 2) is used, also overlaps with cluster 1, and is fundamentally focused on computational fluid dynamics connecting aerospace engineering (cluster 2), mainly aerodynamics and wind tunnels (cluster 1). Cluster 7 (33 items) located in the bottom, is derived from the topic of aerospace engineering (cluster 2) and is related to the launch of satellites.

On the other side, the keywords of mobile robots, robotics, robots and motion planning from cluster 6 (38 items) are connected to space research and aerospace engineering (cluster 2 ) by one side and, by other the keyword digital technologies directly to cluster 2 via the term aerospace engineering.

Finally, the third group (2010-) of the overlay visualization (Figure 1) is dominated by the cluster 8 (20 items), and the cluster 3 ( 54 items), such as Figure 2 illustrates. In cluster 8 , the use of cloud computing is highlighted (Table 2). There are two defined sub-groups of keywords without any overlapping among them in this cluster. This separation can be an indicator of an unexplored research area. One sub-group is linked to cluster 6 (38 items) by the curriculum design of engineering education and cluster 2 via the term aerospace engineering and, another connected via this keyword, which is focused on cloud computing and hardware. Cluster 3 (54 items) is characterized by the digital technology of mobile devices (Table 2) and also, three dimensional. Other keywords in this cluster are mobile devices, clouds, $3 d$ point cloud, algorithms, data visualization, image processing, remote sensing, atmospheric, high resolution and, meteorology. Cluster 9 (4 items), focuses on experimental investigations and helicopters, is located in this group.

Table 2

Big Five Digital technologies in the clusters with 3 co-words

\begin{tabular}{|c|c|c|c|c|c|}
\hline Digital technology & $\begin{array}{l}\text { Number of } \\
\text { cluster }\end{array}$ & $\begin{array}{l}\text { Number } \\
\text { of items }\end{array}$ & $\begin{array}{c}\text { Number } \\
\text { links }\end{array}$ & $\begin{array}{c}\text { fTotal link } \\
\text { strength }\end{array}$ & Occurrences \\
\hline Big data & cluster 2 & 1 & 20 & 26 & 6 \\
\hline Cloud computing & cluster 8 & 1 & 37 & 82 & 7 \\
\hline Internet of Things (IoT) & & 2 & 11 & 13 & 3 \\
\hline Mobile computing & cluster 2 & 2 & 21 & 28 & 5 \\
\hline Mobile devices & cluster 3 & 1 & 24 & 31 & 8 \\
\hline $\begin{array}{l}\text { global system for } \\
\text { mobile communications }\end{array}$ & cluster 4 & 1 & 17 & 18 & 3 \\
\hline Mobile device systems & cluster 5 & 1 & 24 & 44 & 5 \\
\hline Mobile robots & cluster 6 & 1 & 65 & 134 & 27 \\
\hline
\end{tabular}

Items: 372 , clusters: 9, links: 4956, total link strength: 8254.

The results offered by cluster 1 and cluster 7 could be conditioned by the use of the keyword cloud instead of the term cloud computing.

Nevertheless, it has allowed enriching the meaning of the cluster in a general network analysis of the research field. 


\section{The Conceptual Structure of Co-Word in 8}

With the minimum number of occurrences of a keyword established in 8 , of the 4,513 keywords, 59 meet the threshold and 6 clusters emerged (Figure 3).

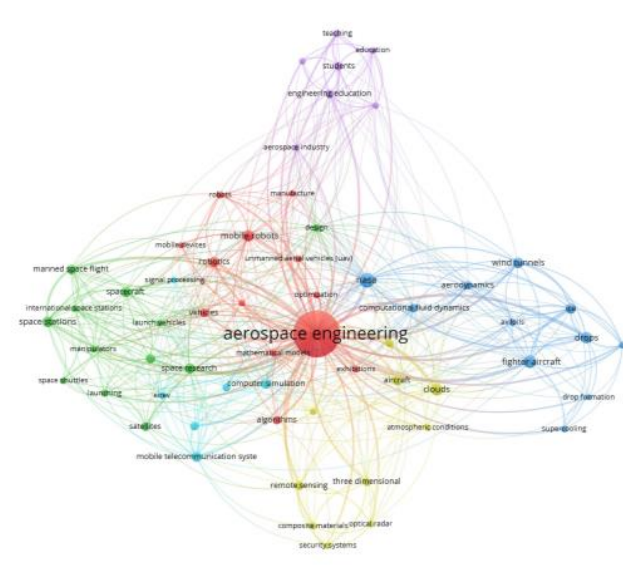

Figure 3. Network co-words (8).

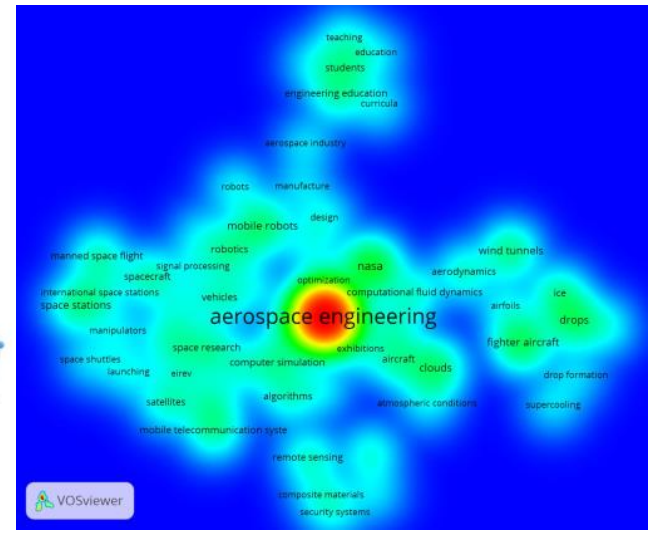

Figure 4. Density co-words (8).

Cluster 1, in red with 13 items, is related to robotics: aerospace engineering, algorithms, exhibitions, manufacture, mathematical models, mobile devices, mobile robots, optimization, robotics, robots, tracking (position), unmanned aerial vehicles, vehicles. This cluster includes papers $(\mathrm{n}=10)$ related to digital technology mobile robots, with 3 articles (Table 3$)$. The most cited article in this cluster $(\mathrm{n}=56)$ is from Acta Astronautica, and is related to the maintenance operations on the International Space Station (ISS) (Coleshill et al., 2009). Concerning the citation report on Scopus, the paper related to the first experiments with PK-3 Plus on the International Space Station (ISS) (Thomas et al., 2008) has 125 citations. Taking into account that cluster 1 can be considered the main cluster and the central position that occupies aerospace engineering in the whole network, the contribution of this keyword to the network structure is significant.

This cluster is located between cluster 2, in green, which includes 12 keywords (i.e. design, launch vehicles, satellites and space stations) related to the design and cluster 5 (purple, 7 items) referred to the curricula and the teaching in engineering education. The graph of cluster 5 shows strong links among the keywords engineering education, students, education and teaching. The keyword, aerospace industry, is also included in this cluster.

Cluster 5 has defined boundaries without overlaps suggesting that the study of the curriculum design and teaching in the aerospace industry related to the use of the Big Five technologies is an unexplored research area. This gap is evident concerning cluster 5, almost isolated, in the overlay visualization of the network (Figure 4). Cluster 3, in blue, with 11 items is focused on aerodynamics (i.e. fighter aircraft, NASA, wind tunnels). Figure 4 indicates that there are at least two sub-groups in this cluster. One focused on 
aerodynamics and wind tunnels and another one, on drops. Cluster 4, in yellow, with 10 items, is related to the atmospheric conditions of flight dynamics and security systems (i.e., aviation, clouds, composite materials, remote sensing). The keyword highlighted in this cluster is three dimensional included in two proceeding papers.

One of them addressed the software simulator for the robotic exploration of the lunar surface (Lombardi, Lavagna, \& Francesconi, 2009) and, another one discussed a new approach for automatic registration of 3D point clouds using the genetic algorithm (GA) (Mariano \& Li, 2012).

Algorithm is a keyword of the main cluster 1, related to robotics. In fact, cluster 4 is located between this main cluster, cluster 3 about aerodynamics and cluster 6 , reinforcing is identification like a bridge.

One article mentioned the 3D technology, describing the challenges in the future aerospace systems and the aerospace engineering education (Noor, 2011). Most of the articles included in this cluster are related to the clouds as atmospheric conditions, or the description of strategic, tactical and task cloud of aircraft mission system (Wang, Gu, Wu, \& Wang, 2015).

After filtering the dataset with the cloud technology (Table 3), three articles emerged. The first article was about mobile cloud and cloud computing (Cortes \& Rabelo, 2013), another described the implementation to cloud memory of flight data recorders from an internal embedded device (Wiseman, 2016) and the article more cited $(n=3)$ reporting the effectiveness of the application of cloud technology in manufacturing for aerospace complex products (Lin et al., 2016).

Finally, cluster 6 (light blue, 6 items), overlapped among cluster 2 and cluster 1 , is related to the communication systems and signal processing of avionics (i.e., avionics, satellite communication systems). The digital technology identified in this cluster is the mobile telecommunication systems. Two conferences papers included this digital technology as keyword (Table 3): one is a recommendation and implementation guidance to Grid installations (Hoeft \& Epting, 2007) and, another one is a methodology for EMC testing and for characterizing NFC devices and their emissions according to aircraft industry standards (Nalbantoğlu et al., 2016). Also, this cluster mentions the computer simulation technology about the Spectral IR Imaging of Targets and Scenes (SPIRITS) (Scott, 1990). The digital technologies used in this key research streams $(n=8)$ are focused on cloud computing (Big Five) and mobile, specifically devices, robots and telecommunications (Table 3 ). 
Table 3

Big Five technologies by clusters with 8 co-words

\begin{tabular}{lccccc}
\hline \multicolumn{1}{c}{$\begin{array}{c}\text { Digital } \\
\text { technology }\end{array}$} & $\begin{array}{c}\text { Number of } \\
\text { cluster }\end{array}$ & $\begin{array}{c}\text { Number of } \\
\text { items }\end{array}$ & $\begin{array}{c}\text { Number of } \\
\text { links }\end{array}$ & $\begin{array}{c}\text { Total link } \\
\text { strength }\end{array}$ & Occurrences \\
\hline $\begin{array}{l}\text { Cloud computing } \\
\text { Mobile devices }\end{array}$ & cluster 4 & 1 & 25 & 68 & 28 \\
$\begin{array}{l}\text { Mobile robots } \\
\begin{array}{l}\text { Mobile } \\
\text { telecommunicati }\end{array}\end{array}$ & cluster 1 & 2 & 11 & 18 & 8 \\
on & & & 27 & 80 & 27 \\
\hline
\end{tabular}

Items: 59, clusters: 6, Links: 556, Total links strength: 1803.

\section{Keyword Centrality Analysis}

The 8 co-words network characteristics were analyzed at micro-level (Table 4). The higher value of the betweeness centrality (BC) measure (BC Sum $=12.000 ; \mathrm{BC}^{\prime}$ classes $=2 ; \mathrm{BC}^{\prime}$ Sum $=0.007 ; \mathrm{BC}^{\prime}$ Mean $=0.000 ; \mathrm{BC}^{\prime}$ Variance $=0.000)$ of Aerodynamics $\left(\mathrm{BC}^{\prime}=0.007\right)$ indicates that this keyword bridge clusters. These results are corroborated by the Power Centrality (PC) index $\left(\mathrm{PC}\right.$ Sum $=664.000 ; \mathrm{PC}$ classes $=2 ; \mathrm{PC}^{\prime} \mathrm{Sum}=58.000 ; \mathrm{PC}^{\prime}$ Mean $=$ $0.983 ; \mathrm{PC}^{\prime}$ Variance $=0.017$ ) in which the keyword Aerodynamics has the maximum value (Max $\mathrm{PC}^{\prime}=1.000$ ). Meaning that Aerodynamics is a concept connected to all (star), that can be interpreted as an evidence of their influential power in the future. Furthermore, Figure 5 shows the keyword Aerodynamics (links: 24, total link strength: 59, occurrences: 16) occupying a central position in the cluster 3 .

Meanwhile, the term Aerospace has the minimum value in both measures (Min $\mathrm{BC}^{\prime}=0.000$; Min $\mathrm{PC}^{\prime}=0.000$ ). However, the values of the degree centrality $\left(\mathrm{DC}\right.$ Sum $=3606.000 ; \mathrm{DC}^{\prime}$ classes $=41 ; \mathrm{DC}^{\prime}$ Sum $=1.000$; $\mathrm{DC}^{\prime}$ Mean $=0.017 ; \mathrm{DC}^{\prime}$ Variance $\left.=0.001\right)$ and the Influence Range Closeness Centrality $($ IRCC classes $=30 ;$ IRCC Sum $=367.831$; IRCC Mean =6.234; IRCC Variance $=1.823)$ of the keyword Aerospace are the highest $\left(\mathrm{DC}^{\prime}=\right.$ 0.224 ; IRCC $=11.739$ ). Since, the IRCC index considers how proximate each node is to the nodes in its influence range and DC indicates the number of direct ties an item has with others in the network, the high value of Aerospace in the network can be interpreted as easy access to any resource, such as information and knowledge of high-quality. On the contrary, the terms mobile $\left(\mathrm{DC}^{\prime}=0.005\right)$ and curricula $(\mathrm{IRCC}=4.521)$ have the minimum value.

In relation to EVC (Table 4), the keyword NASA has the maximum value $(\mathrm{EVC}=0.255)$ of the report centrality eigenvector $(\mathrm{EVC}$ classes $=0$; EVC Sum $=7.165 ;$ EVC Mean $=0.121 ;$ EVC Variance $=0.002)$, indicating its relevance in the network (Wasserman \& Faust, 1994). The minimum value belongs to the keyword Composite (Min $\mathrm{EVC}=0.028$ ). In relation to this, Aerodynamics has a medium value $(\mathrm{EVC}=0.135)$.

Since there was no way to compute Group Eigenvector Centralization, Variance was used as a general centralization index. This network can be 
considered as almost a complete or circle graph since the value of variance (0.002) suggests minor variability between the EVC' values.

Table 4

The network characteristics of the co-word matrix $(n=8)$

\begin{tabular}{|c|c|c|c|c|c|c|c|c|c|c|}
\hline Rank & Label & $\mathrm{DC}^{\prime}$ & Label & $\mathrm{BC}^{\prime}$ & Label & IRCC & Label & $\mathrm{PC}^{\prime}$ & Label & EVC \\
\hline 1 & Aeros & 0.224 & Aerod & 0.007 & Aeros & 11.739 & Aerod & 1 & NASA & 0.255 \\
\hline 2 & NASA & 0.037 & Aeros & 0.000 & NASA & 9.161 & Winds & 1 & Robotics & s 0.222 \\
\hline 3 & Fighte & 0.029 & Aircraft & 0.000 & Fighte & r 8.698 & Design & 1 & Design & 0.212 \\
\hline
\end{tabular}

DC, Degree centrality; BC, Betweenness centrality; IRCC, Influence Range Closeness; PC, Power Centrality; EVC, Eigenvector centrality index. Aeros: Aerospace, Aerod: Aerodynamics.

The visualization of the keyword NASA (cluster 3, 42 links, total link strength:134, occurrences:43) in the whole network (Figure 6) illustrates its relevance and also, its access to other resources of the research field. This interpretation is reinforced by its $0.037 \mathrm{DC}^{\prime}$ value (Table 4) and, that the most cited paper $(n=210)$, in the whole dataset $(n=447)$ of Scopus, is related to the preliminary results of the Lidar In-space Technology Experiment (LITE) of NASA in 1996 (Winker, Couch, \& Mccormick, 1996). It is followed by a working robot system research $(n=151)$, which applies the same frames of references that of astronauts working on a collaborative project (Trafton et al., 2005). The keyword robotics (cluster 1, 29 links, total link strength: 65, occurrences: 20) has an important second position in the Eigenvector centrality index $(\mathrm{EVC}=0.222)$. The item design (links: 32, total link strength: 61, occurrences: 12) from cluster 2, is key in the relevance of the Aerodynamics and NASA because of its position as a bridge with cluster 3 (Figure 5 and Figure 6). Not surprisingly, it has the third highest value in the report centrality eigenvector $(\mathrm{EVC}=0.212)$.

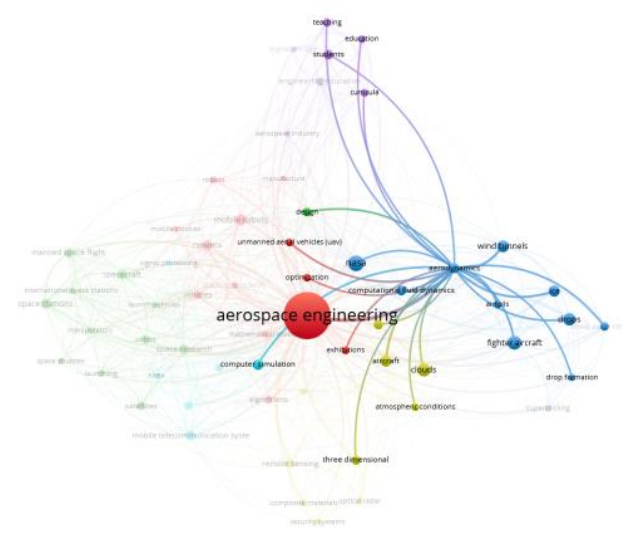

Figure 5. Aerodynamics keyword.

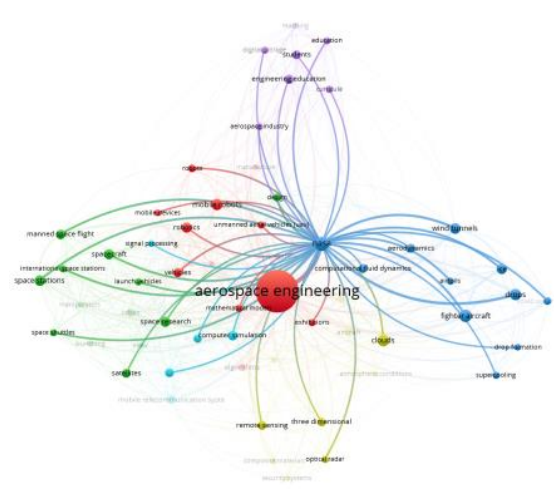

Figure 6. NASA keyword.

The current study significantly differs from previous results reported 
(Pelicioni et al., 2018); the delimitation of the technology to the Big Five suggests that aerospace development research is focused on Aerodynamics and NASA.

\section{Categorization of the Big Five Digital Technologies}

Mobiles are the most common technology identified in the overall dataset (Table 5). Due to the results of the cluster analysis in both co-word, a distinction between the type of mobile reference was made. 87 records were initially classified as mobile technology in general, among them: mobiles related to satellite communications, mobile applications, mobile devices, mobile lab, mobile robot, mobile simulation and mobile telecommunications system. Concerning mobile robot, eight articles from a total of 49 papers were identified (Table 5). The first mention appeared in a conference paper in 1985; it was related to three mobile fire-fighting modules for dispersing warm fog.

The first article was published in 1992, "a mobile testing laboratory developed to be transported to a vehicle's location" (Bata et al., 1992). Only one article was related to social aspects and security of mobile communication systems in the French aerospace group (Anderson, 2006). Five conference papers were identified in this dataset on education.

The first mention of mobile telecommunications is from an article published in 1975. It is included in the previously mentioned volume entitled "technology for change" (Anon, 1986). The mobile devices digital technology is discussed in 8 conference papers. Two of them are related to education: a Laboratory of Remote Access that can be used for courses in aeronautical engineering (Sievers Jr., Rangel, \& Neto, 2014) and a paper describing the activity project "Look App" conducted by a group of students from the Departments of Aerospace Engineering and Astrophysics from SapienzaUniversity of Rome (Pellegrino et al., 2015).

The first mention of digital technologies (Table 5) appeared in an article published in 1975 in a volume entitled "technology for change" related to mobile communications via satellite (Anon, 1975). The next article appeared in 1986, addressing the configuration of the communication link between shore stations and mobile with satellites (Bitzer, Toussaint, Riffaldi, $\&$ Saitto, 1986). The first conference paper mentioning this digital technology was related to mobile space platform and was published in 1983. It referenced the Fairchild Leasecraft system, the shuttle-launched and supported mobile mini space platform to conduct peaceful activities within and outside the atmosphere (Burrowbridge, 1983). The 3G mobile via-satellite services mentioned at a conference in 2003 is considered the first paper about digital technologies (Anon, 1986).

The first article related to mobile digital technology was also published in 2003. It discussed the development of aeronautical GSM systems and their integration with onboard systems (Fitzgerald, 2003). 3D technology, is described in 1990 like a "three-dimensional model for an artificial plasma cloud in the ionosphere" (Gatsonis \& Hastings, 1990) in conference 
proceedings. As for articles, the only one mentioned was in 2011, which proposed the development of a personalized /collaborative ecosystem for the aerospace workforce (Noor, 2011).

The first mention of cloud computing was in 2013. The conference paper of Xu, Bil and Cai (2013) presented a framework for aerospace engineering education based on cloud computing. The relevance of this proposal lies in the collaborative aspect with the integration of Web 2.0 technologies as Google Drive, SkyDrive, Dropbox, Google Talk and Skype. Three articles have been identified using cloud computing technology (Table 5). The first article is from the same year, a case study of the application of tablet computing in the cloud for operations in spacecraft systems (Cortes \& Rabelo, 2013).

The most cited paper related to the digital technology of Big Data appeared in 2014, and is related to a framework complementing periodical localized inspections to continuous network-wide health monitoring (Wang, Birken, \& Shahini Shamsabadi, 2014). There are seven papers including specific references to digital technology (Table 5). The first reference appears in 1988 in the IEEE National Aerospace and Electronics Conference (NAECON, 1988) it contains 236 papers by various authors. The last one published in 2015 is a conference paper considering the digital technologies skills of first-year engineering students to develop a flipped teaching methodology with the combination of computer technologies and face-to-face classes in the first year Mathematics course in Aerospace Engineering (Llobregat-Gómez, Moraño, Roselló, \& Ruiz, 2015). The IoT concerning aeronautical engineering appeared in an article of 2015, under a theoretical approach for the development of the transportation industry and the traffic (Zhang, 2015).

In relation to Web 2.0 technologies, the first reference in 2010 belongs to the most cited conference paper in this category $(n=6)$ presenting the results of using educational videos in the Moodle platform, combined with text, images and questionnaires. The findings highlighted the increase of motivation from students (Simo et al., 2010). Also relevant in this category is a publication in 2015 related to the NASA innovation ecosystem as a collaborative platform whose team uses social media (Hardash, Landegger, Decker, \& Thompson, 2015). Finally, the last publication in 2016 refers to the self-regulation strategies of two mechanical and aerospace engineering courses using Google Docs and Box were analyzed by mixed methods approach (Lawanto \& Febrian, 2016). The technologies included in 'others' were excluded from further analysis since this topic covered technologies out of the scope of the search string defined. For example, computational technologies (8 conference papers, 1 article), laser ( 3 conference papers), radar technologies (1 article), teleoperator technology (1 conference paper), tunnel technologies (1 conference paper), simulations and virtual building prototype (1 review). 
Table 5

Categorization of articles by type of digital technology

\begin{tabular}{lllllll}
\hline \multicolumn{1}{c}{ Type } & FYC & LYC & NA & FYA & LYA & Total \\
\hline Digital technology & 1988 & 2015 & - & - & - & 6 \\
3D technology & 1990 & 2017 & 1 & 2011 & - & 15 \\
Mobile robot & 1985 & 2018 & 8 & 1992 & 2017 & 49 \\
Mobile devices & 2007 & 2017 & 8 & - & - & 8 \\
Mobile telecommunication & 2003 & 2017 & 5 & 1975 & 2006 & 10 \\
Web 2.0 & 2010 & 2016 & - & - & - & 3 \\
Cloud computing & 2013 & 2016 & 3 & 2013 & 2016 & 13 \\
Big data & 2014 & 2017 & - & - & - & 7 \\
Internet of things (IoT) & 2014 & 2017 & 1 & 2015 & - & 4 \\
\hline
\end{tabular}

$\overline{\text { FYC, First year publication conference review or paper; LYC, Last year publication }}$ conference review or paper; NA, Number of articles; FYA, First year publication article; LYA, Last year publication article; Total: number of conference papers and articles.

\section{Design-Based Research Intervention}

With the documents related to education from the first, second search string (Table 1.2) and bibliographic references stored in Mendeley in RIS format ( $\mathrm{n}=86$ ), full keyword co-occurrences were performed in VoSviewer. With the minimum number of occurrences of a keyword in 2, of the 396 keywords, 53 meet the threshold. For each of the 53 keywords, the total strength of the co-occurrence links with other keywords was calculated, and the keywords with the greatest total link strength were selected. The terms grou, co, in were eliminated from the verification of selected keywords. This analysis was compared to the number of occurrences established in 3 (Table 6). Of the 396 keywords, 21 meet the threshold (clusters 5, links 65, total link strength 150).

These articles can be considered the core of the academic research in the use of the Big Five technologies in aeronautical engineering. Figure 7 includes an overlay visualization of the network $(n=2)$ which offers more detail to the analysis. 
Table 6

Keyword co-occurrence comparative

\begin{tabular}{lll}
\hline \multicolumn{1}{c}{ keyword co-occurrence $(\mathrm{n}=2)$} & \multicolumn{1}{c}{ keyword co-occurrence $(\mathrm{n}=3)$} \\
\hline $\mathrm{C} 1 \quad \begin{array}{l}\text { Alabama, Capstone design, class } \\
\text { projects, computer aided design, } \\
\text { computer software, design, engineering } \\
\text { design, engineering education, } \\
\text { engineering research }\end{array}$ & $\begin{array}{l}\text { aerospace industry, curricula, } \\
\text { design, education, engineering, }\end{array}$ & students \\
\end{tabular}

C2 Air navigation, artificial intelligence, avionics, big data, data handling, eirev, information

aerospace engineering, big data, computer aided design, engineering education, space

C3 Aerospace control, dedicated blended learning, e-learning, computers, e-learning, geographical positions, grou, information systems, unmanned aerial vehicle

C4 Aerodynamics, aerospace industry, artificial intelligence, avionics, mathematics, capstone design course, computer curricula, engineering, technology

C5 Classroom education, cloud computing, classroom education, cloud collaborative work, computer, computer, computing, collaborative work concurre

C6 Aerospace, algorithms, blended learning, distance education, education, students

C7 aerospace engineering, aerospace engineers, information management, research

C8 Ambient intelligence, driver, immersive, learning environment

C9 Space

A comparative co-word analysis (Table 6) highlights the dynamics of the conceptual structure of topics and their evolution. The dynamic analysis of the networks allows to highlight the permanence of the digital technologies identified and also, their significance related to the clusters (Table 6). Big Data keeps is position in cluster 2 in both co-word analysis (Table 6) although the associated keywords evolve to more specific research in computer-aided design in engineering education. This evidence supports previous research suggesting that an evolution in the design processes will involve the use of the computer (Marshall, 1980). Cloud computing (cluster 5) appears as frequently studied together with classroom education and collaborative work (Table 6).

The overlay visualization of the academic papers related to education (Figure 7) illustrates the evolution of the use of digital technologies. From 
both thresholds, the Big Five technologies identified in relation to education were Big Data (avg.pub.year: 2017) and cloud computing (avg.pub.year: 2012). The position of cloud computing as a bridge is relevant (Figure 7). Other digital technologies mentioned are Artificial Intelligence (avg.pub.year: 1998) and computer (avg.pub.year: 2006). As indicated in previous research (Zawacki-Richter \& Latchem, 2018), the evidence of this study points to a progression of collaborative work and e-learning (Figure 7). Finally, despite the term Aerodynamics being mentioned (Table 6; Cluster 4) in the co-word $(\mathrm{n}=2)$ and studies relating the use of micro-computers to teach aerodynamics analysis (Zuppardi \& Napolitano, 1987), there is a lack of evidence concerning the Big Five technologies.

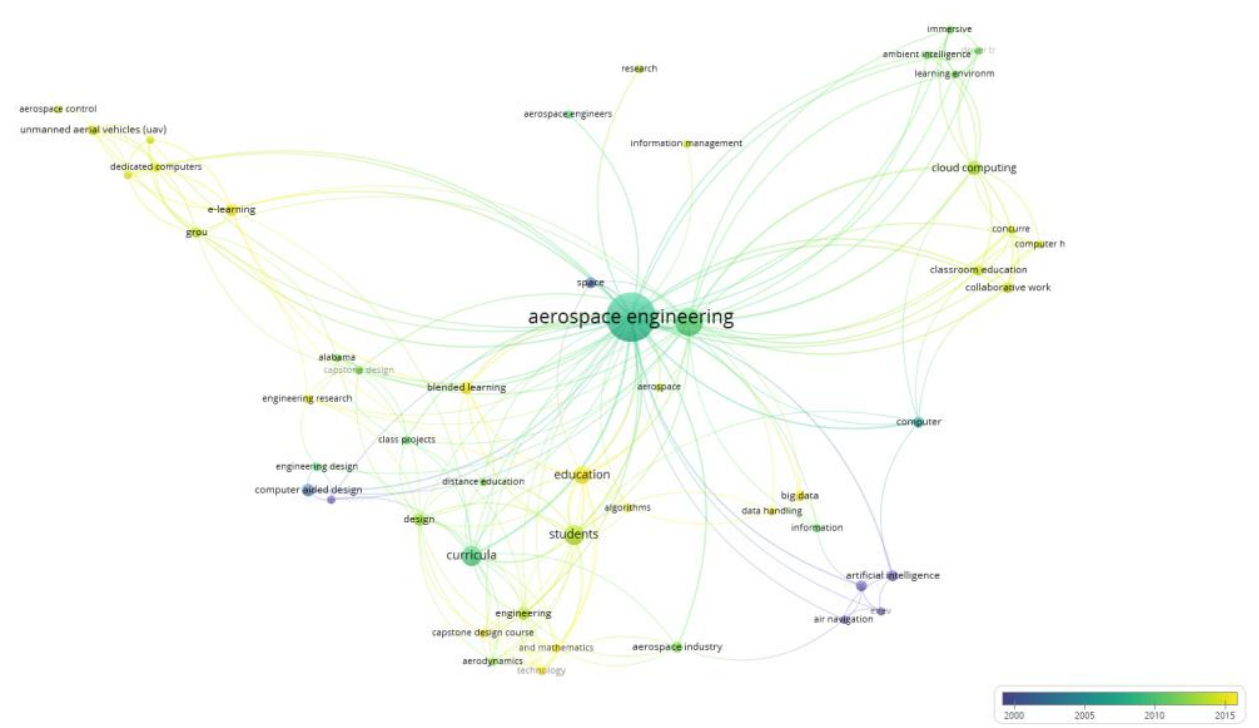

Figure 7. Overlay co-word $(\mathrm{n}=2)$ academic papers related to education.

Peer-reviewed academic papers were selected and analyzed from a design-based research approach. From the first search string (1), out of the 39 papers, 2 duplicates were removed. Only articles were selected for further analysis $(\mathrm{n}=18), 6$ articles were excluded for not being identified as designbased research studies intervention. A total of 11 articles were classified under the design-based research methodology (Table A1). From the second search string (2), out of the 23 articles selected for design-based research analysis, only 7 were identified as DBR (Table A2). The excluded articles were the duplicated and, 1 without access (Pan, Jin, \& Feng, 2015). From the 18 articles selected for the design-based research analysis, the majority of the sample address undergraduate students $(n=7)$. Concerning the intervention type, six articles of the ones using the instructional approach $(n=10)$ reported the research sample of undergraduate students and also those addressed to graduates $(n=3)$. Technological testing effectiveness $(n=7)$ is the second type of intervention more reported in the dataset. 
The digital technologies identified in the DBR analysis (Table A1; Table A2) were Web 2.0, as Big Five Technology, (Cervone, Melkert, Mebus, \& Saunders-Smits, 2016; Jordana \& Josep-Robert, 2015; Rodríguez-Sevillano et al., 2016) and, robotics (Boles, Bernold, \& Scott, 1995; Carmen, 2012; Joshi, 2004).

Two of the three articles reporting the use of Web 2.0 (Cervone et al., 2016; Rodríguez-Sevillano et al., 2016) indicated the application of a blended learning methodology. For instance, the case study of Cervone et al. (2016) specifically reported the use of the flipped classroom methodology with interactive, practical examples and video lectures in the "Propulsion and Power" course offered in the Aerospace Engineering Bachelor degree programme. The experiences reported by Rodriguez-Sevillano et al. (2016) indicated that the Web 2.0 digital tools used in the "Introduction to Engineering Helicopter" course are the ones included in Learning Management Systems and Massive Online Open Courses (MOOCs) such as, online activities, video lectures, wikis and blogs.

Finally, the research of Jordana and Josep-Robert (2015) reported the use of Google sites for the creation of student e-portfolios and their work as a cooperative group applying the Problem Based Learning (PBL) methodology in the teaching of "Digital Circuits and Systems" (CSD) in Aerospace Engineering. All of them reported the instructional approach strategy and the motivation improvement of the students as a result of this DBR intervention type.

The results of the face-to-face instructional approach strategy intervention followed by three academic papers using robotics indicated the new understanding about educational phenomena (Carmen, 2012; Joshi, 2004) and the improvement of student attitude (Boles et al., 1995; Joshi, 2004).The MATLAB computer simulation course project implemented as part of an introductory graduate course in autonomous robotics with students from Mechanical and Aeronautical Engineering, among others (Joshi, 2004) reported on the creativity stimulus and collaborative advantages of this approach. Most of the articles identified as DBR included the use of simulations ( $n=11)$ and 3D printing $(n=2)$, in the definition of the Big Five technologies used in this scoping review.

Despite the previous research having highlighted the need for knowledge of computers to work in aerodynamics, aerospace materials, flight mechanics among others, like propulsion, stability and control (Long, 2015), the findings of this study suggest that within the Big Five technologies, only the Web 2.0 (social media) is used in the teaching of aeronautical engineering. With the exception of a few articles mainly reporting the use of simulation (Ahmed, 2014) and robotics (Boles et al., 1995; Joshi, 2004), there is an absence of evidence in the peer-reviewed literature to support previous research arguing that the evolution of the technologies will affect taskorientated training (Van Der Heiden et al., 2015). 
The current study significantly differs from previous results reporting the important role of technology in universities on the development of space technologies (Pelicioni et al., 2018). Considering that a different selection of digital technologies could offer other results, further research could focus on different digital technologies, such as Augmented and Virtual Reality (AR/VR), robotics (Xia \& Zhong, 2018) or Artificial Intelligence, among others as Virtual Worlds (Okutsu, DeLaurentis, Brophy, \& Lambert, 2013), to enrich the findings. Similarly, a future study about the use of Web 2.0 technologies should be based on a previous classification mentioning the specific tools included.

\section{Conclusions}

This study provides a scoping review of the literature on the digital technologies identified as the Big Five used in aeronautical engineering and facilitates the identification of educational interventions to update future research and to inform education policy development. The Social Network Analysis describing the relevant research themes and trending topics in relation to the field has allowed understanding how the use of digital technologies and specifically, those identified as the Big Five technologies, in aeronautical engineering are being used and implemented.

The findings reveal that at the macro and micro-level of the Social Network Analysis, NASA and aerodynamics are the trending topics of the research field. The broad perspective provided by the conceptual structure of co-word $(n=3)$ analysis allowed to identify three periods of evolution in relation to the use of the Big Five technologies. The Big Data and IoT (20022008) appeared as highly correlated keywords with aviation. Also, it appears that cloud computing (2010-) is used in the curriculum design of engineering education. The relevance of the term cloud computing is reinforced by the results with the higher threshold of the co-word analysis $(\mathrm{n}=8)$, as an associated keyword of Aerodynamics. However, none of the Big Five technologies was identified in the keyword centrality analysis.

The categorization of the Big Five technologies in the overall dataset revealed documents mentioning the Web 2.0 (2010), cloud computing (2013), the Big Data (2014) and, the IoT (2014). The co-word analysis of academic papers explicitly related to education allowed to identify the Big Data (2017) and cloud computing (2012) use of the Big Five technologies. Nevertheless, the analysis of interventions using the Big Five technologies by a design-based research approach of the academic papers only revealed the use of the Web 2.0 since 2015.The evidence from this study suggests from different metrics and approaches, that despite the references to the Big Five technologies in the aeronautical engineering field, only Big Data and cloud computing has been identified in education. Furthermore, the lack of empirical educational intervention references, except for the Web 2.0 included in the delimitation of social media, is relevant.

Previous research did reveal that a time lag can exist on application 
research reports in the educational context and a new technology (ZawackiRichter \& Latchem, 2018).

The results of this scoping review show that the digital technology adoption from education in the aeronautical engineering field is still developing. Nevertheless, further studies taking into consideration other digital technologies such as robotics, virtual reality, or augmented reality are desirable to analyze the evidence of interventions in aeronautical engineering education. It is recommended to analyze the knowledge of the Big Five technologies of the teachers and their use in the teaching, as well as its integration in the aeronautical engineering curriculum. These topics are the subject of future research.

The scoping review approach is enriched with a Social Network Analysis, a keyword centrality analysis and, a design-based research analysis. The methodology followed has clear advantages by identifying the knowledge structure and the evolution of topics at the macro and micro level of a research field. The combination of a low and a higher threshold of the network has allowed describing the dynamics of the research field, following the evolution of the clusters to a more fine-grained analysis. The methodological approach of this study has shown how the incorporation of quantitative methods based on Social Network Analysis with qualitative approaches such as description and interpretation of the features of the design-based research implementation can be used to enrich reviews and analyze technology change.

However, the findings have to be interpreted with caution, because quality assessment does not form part of the scoping review. Because only English records were included in the search string, a risk of bias in the search process is possible. Furthermore, the authors of the articles reviewed should be contacted for missing information in future research. This review could be used to further assess educational interventions in aeronautical engineering that use digital technologies. The exploration of the conceptual structure from both the macro and micro-level provide an original way to review the literature and identify the use of digital technologies in the field. 


\section{References}

Ahmed, N. A. (2014). Blending conventional methods with emerging flight simulation technology as tools for effective teaching and learning experiences in aerospace engineering. In Using Technology Tools to Innovate Assessment, Reporting, and Teaching Practices in Engineering Education (pp. 21-39). http://doi.org/10.4018/978-1-4666-5011-4.ch003

AIAA Association (AIAA). (2018). The aerospace research central (ARC). Retrieved from https://arc.aiaa.org/

Altran. (2018). The aeronautical industry is ready for the digital revolution. Retrieved from http://ignition.altran.com/en/article/aeronautical-industryready-digital-revolution/

Anderson, G. (2006). Safran warns on implications of fraud probe. Jane's Defence Weekly. Retrieved from https://www.researchgate.net/ publication/291632129_Safran_warns_on_implications_of_fraud_probe

Anon. (1975). EASCON '75: IEEE Electron and Aerosp Syst Conv (EASCON '75) Rec Pp. Var Paging, Retrieved from https://ieeexplore.ieee.org/ stamp/stamp.jsp?arnumber=4103645

Anon. (1986). Proceedings of the IEEE 1986 National Aerospace and Electronics Conference, NAECON 1986. In IEEE Proceedings of the National Aerospace and Electronics Conference. IEEE, New York, NY, USA. Retrieved from https://www.tib.eu/en/search/id/TIBKAT\% 3A479868344/Proceedings-of-the-IEEE-1986-National-Aerospace/

Arksey, H., \& O’Malley, L. (2005). Scoping studies: Towards a methodological framework. International Journal of Social Research Methodology: Theory and Practice, 8(1), 19-32. http://doi.org/10.1080/1364557032000119616

Barbosa, A., Buck, M., Chiassarini, G., De Gaudenzi, R., Geracitano, G., Perez-Carro, A., ... Widmer, H. (2003). Via-satellite trials of W-CDMA multimedia broadcasting and interactive packet access: The ESA Advanced Test Bed (ATB) project (pp. 297-307). Frascati. Retrieved from http://adsabs.harvard.edu/abs/2003ESASP.541E..42B

Bata, R., Clark, N., Gautam, M., Howell, A., Long, T., Loth, J., ... Wang, W. (1992). Transportable emissions testing, 100(1), 31-35. Retrieved from https://www.researchgate.net/publication/296780002_Transportable_emis sions_testing

Bitzer, K. L., Toussaint, M., Riffaldi, D., \& Saitto, A. (1986). Extension of the Inmarsat coverage to the polar caps: A system trade-off., 6(2), 231-242. Retrieved from http://adsabs.harvard.edu/abs/1984laus.iafcW....B

Boles, W. W., Bernold, L. E., \& Scott, W. D. (1995). Lunar shelter student contest: Exciting education for civil engineers. Journal of Professional Issues in Engineering Education and Practice, 121(4), 225-230. http://doi.org/10.1061/(ASCE)1052-3928(1995)121:4(225)

Bruno, M. (2016). Pitfalls seen in aerospace \& defense digitization. Retrieved 1 July 2018, from http://aviationweek.com/future-leaders/pitfalls-seenaerospace-defense-digitization 
Burrowbridge, D. R. (1983). Leasecraft: A commercial space platform. Sioux Falls, ND: Augustana Coll, Retrieved from https://www.researchgate.net/ publication/234358379_Leasecraft_-_A_commercial_space_platform

Callon, M., Courtial, J. P., \& Laville, F. (1991). Co-word analysis as a tool for describing the network of interactions between basic and technological research: The case of polymer chemistry. Scientometrics, 22(1), 155-205. http://doi.org/10.1007/BF02019280

Carmen, C. (2012). Integration of a NASA faculty fellowship project within an undergraduate engineering capstone design class. Acta Astronautica, 80, 141-153. http://doi.org/10.1016/j.actaastro.2012.05.031

Cervone, A., Melkert, J. A., Mebus, L. F. M., \& Saunders-Smits, G. N. (2016). Push or pull students into blended education: A case study at Delft University of Technology. International Journal of Engineering Education, 32(5), 1911-1921. Retrieved from https://repository.tudelft.nl/ islandora/object/uuid\%3Ac565d5b9-ab6f-4b49-a8a0-07d5a57c2b71

Coleshill, E., Oshinowo, L., Rembala, R., Bina, B., Rey, D., \& Sindelar, S. (2009). Dextre: Improving maintenance operations on the International Space Station. Acta Astronautica, 64(9-10), 869-874. http://doi.org/10.1016/j.actaastro.2008.11.011

Colicchia, C., Creazza, A., \& Strozzi, F. (2017). Citation network analysis for supporting continuous improvement in Higher Education. Studies in Higher Education, 5079, 1-17. http://doi.org/10.1080/03075079.2016.1276550

Collins, A., Joseph, D., \& Bielaczyc, K. (2009). Design research: Theoretical and methodological issues. Journal of the Learning Sciences, 13, 15-42. http://doi.org/10.1207/s15327809j1s1301

Cortes, E. A., \& Rabelo, L. (2013). An architecture for monitoring and anomaly detection for space systems. SAE International Journal of Aerospace, 6(1), 81-86. https://doi.org/10.4271/2013-01-2090

Cozzens, S., Gatchair, S., Kang, J., Kim, K. S., Lee, H. J., Ordóñez, G., \& Porter, A. (2010). Emerging technologies: Quantitative identification and measurement. Technology Analysis and Strategic Management, 22(3), 361-376. http://doi.org/10.1080/09537321003647396

Durak, U. (2018). Flight 4.0: The changing technology landscape of aeronautics. Advances in Aeronautical Informatics, 3-13. https://doi.org/10.1007/978-3-319-75058-3_1

Efimenko, I. V, Khoroshevsky, V. F., \& Noyons, E. C. M. (2016). Anticipating future pathways of science, technologies, and innovations approach. In Anticipating Future Innovation Pathways Through Large Data Analysis (pp. 71-96). https://doi.org/10.1007/978-3-319-39056-7_5

Fitzgerald, M. (2003). GSM gets in the cabin. Communications Engineer, 1(4), 14-17. Retrieved from https://ieeexplore.ieee.org/iel5/8515/27695/01235363.pdf

Gatsonis, N. A., \& Hastings, D. E. (1990). A three-dimensional model for an artificial plasma cloud about a spacecraft in low earth orbit. 
https://doi.org/10.2514/6.1990-638

Gonzalez-Teruel, A., Gonzalez-Alcaide, G., Barrios, M., \& Abad-Garcia, M.-F. (2015). Mapping recent information behavior research: An analysis of coauthorship and co-citation networks. Scientometrics, 103(2), 687-705. http://doi.org/10.1007/s11192-015-1548-z

Guffarth, D., \& Barber, M. J. (2017). The evolution of aerospace R\&D collaboration networks on the European, national and regional levels. Innovation Networks for Regional Development, 15-50. http://doi.org/10.1007/978-3-319-43940-2

Hamilton, E. R., Rosenberg, J. M., \& Akcaoglu, M. (2016). The substitution augmentation modification redefinition (SAMR) model: A critical review and suggestions for its use. TechTrends, 60(5), 433-441. http://doi.org/10.1007/s11528-016-0091-y

Hardash, J., Landegger, A., Decker, B., \& Thompson, V. (2015). NASA innovation ecosystem: Host to a government technology innovation network. American Institute of Aeronautics and Astronautics Inc, AIAA. http://doi.org/10.2514/6.2015-1306

Hinchcliffe, D. (2011). The Big Five IT trends of the next half decade: Mobile, social, cloud, consumerization, and big data. Retrieved from https://www.zdnet.com/article/the-big-five-it-trends-of-the-next-halfdecade-mobile-social-cloud-consumerization-and-big-data/

Hoeft, B., \& Epting, U. (2007). Integrated site security for grid; an initiative to cover security beyond the grid (pp. 152-155). IFIP International Conference on Network and Parallel Computing Workshops. http://doi.org/10.1109/ICNPCW.2007.4351477

Igual, R., Plaza, I., José Marcuello, J., \& Arcega, F. (2018). A survey on modeling and simulation practices for teaching power harmonics. Computer Applications in Engineering Education. http://doi.org/10.1002/cae.21959

Infosys. (2017). HfS blueprint report, aerospace engineering services. Retrieved 1 July 2018, from https://www.infosys.com/engineeringservices/features-opinions/Documents/aerospace-engineering-servicesreport.pdf

Janichewski, S. (2017). Why digital technology has become the aircraft industry's favourite theme. Retrieved from https://atos.net/en/blog/digitaltechnology-become-aircraft-industrys-favourite-theme

Jordana, J., \& Josep-Robert, F. (2015). A course on digital electronics based on solving design-oriented exercises by means of a PBL strategy.

International Journal of Engineering Education, 31(1, B, SI), 238-247. Retrieved from https://upcommons.upc.edu/bitstream/handle/ 2117/26325/07_ijee2956ns.pdf

Joshi, S. S. (2004). Development and implementation of a MATLAB simulation project for a multidisciplinary graduate course in autonomous robotics. Computer Applications in Engineering Education, 12(1), 54-64. http://doi.org/10.1002/cae.20001 
Lambiotte, R., Delvenne, J.-C., \& Barahona, M. (2008). Laplacian dynamics and multiscale modular structure in networks. ArXiv Preprint ArXiv:0812.1770, 1-29. http://doi.org/10.1109/TNSE.2015.2391998

Lawanto, O., \& Febrian, A. (2016). Student self-regulation in capstone design courses: A case study of two project teams. Institute of Electrical and Electronics Engineers Inc. http://doi.org/10.1109/FIE.2016.7757481

Lin, T., Yang, C., Gu, M., Li, B., Xiao, Y., Shi, G., \& Xing, C. (2016). Application technology of cloud manufacturing for aerospace complex products. Computer Integrated Manufacturing System, 22(4), 884-898. http://doi.org/10.13196/j.cims.2016.04.002

Llobregat-Gómez, N., Moraño, J.-A., Roselló, M.-D., \& Ruiz, L. M. S. (2015). Blended learning at maths with aerospace engineering freshmen. Institute of Electrical and Electronics Engineers Inc. http://doi.org/10.1109/FIE.2015.7344370

Lombardi, R., Lavagna, M., \& Francesconi, P. (2009). Software simulator for robotic exploration of the lunar surface. International Astronautical Federation. Retrieved from https://iafastro.directory/iac/archive/browse/ IAC-09/A3/I/4457/

Long, L. N. (2015). On the need for significant reform in university education, especially in aerospace engineering. In IEEE Aerospace Conference Proceedings. IEEE Computer Society. http://doi.org/10.1109/ AERO.2015.7119066

Mariano, I., \& Li, X. (2012). Automatic global registration of 3D point clouds for reverse engineering and inspection processes. Applied Mechanics and Materials, 110-116, 4907-4913.

https://doi.org/10.4028/www.scientific.net/ amm.110-116.4907

Marshall, F. J. (1980). A course in computer-aided aerospace design. Computers \& Education, 4(2), 131-137. https://doi.org/10.1016/03601315(80)90015-9

Meho, L. I., \& Yang, K. (2007). Impact of data sources on citation counts and rankings of LIS faculty: Web of science versus Scopus and Google Scholar. Journal of the American Society for Information Science and Technology, 58(13), 2105-2125. https://doi.org/10.1002/asi.20677

Moher, D., Liberati, A., Tetzlaff, J., Altman, D. G., \& Grp, P. (2009). Preferred reporting items for systematic reviews and meta-analyses: The PRISMA statement. Physical Therapy, 89(9), 873-880. http://doi.org/10.1371/ journal.pmed.1000097

Munro, M. (2018). The complicity of digital technologies in the marketisation of UK higher education: exploring the implications of a critical discourse analysis of thirteen national digital teaching and learning strategies. International Journal of Educational Technology in Higher Education, 15(1), 11. http://doi.org/10.1186/s41239-018-0093-2

Naecon. (1988). IEEE 1988 national aerospace and electronics conference. Dayton, OH: IEEE. Retrieved from https://ieeexplore.ieee.org/xpl/ mostRecentIssue.jsp?punumber $=748$ 
Nalbantoğlu, C., Kiehl, T., God, R., Stadtler, T., Kebel, R., \& Bienert, R. (2016). Electromagnetic compatibility (EMC) for integration and use of near field communication (NFC) in aircraft. Institute of Electrical and Electronics Engineers Inc. http://doi.org/10.1109/ AeroEMC.2016.7504559

Noor, A. K. (2011). Intelligent adaptive cyber-physical ecosystem for aerospace engineering education, training and accelerated workforce development. Journal of Aerospace Engineering, 24, 403-408. http://doi.org/10.1061/(ASCE)AS.1943-5525.0000128.

Okutsu, M., DeLaurentis, D., Brophy, S., \& Lambert, J. (2013). Teaching an aerospace engineering design course via virtual worlds: A comparative assessment of learning outcomes. Computers \& Education, 60(1), 288298. http://doi.org/10.1016/j.compedu.2012.07.012

Paez, A. (2017). Gray literature: An important resource in systematic reviews. Journal of Evidence-Based Medicine, 10(3), 233-240. http://doi.org/10.1111/jebm.12266

Pan, W., Jin, L., \& Feng, Z. (2015). Recognition of Chinese characters based on multi-scale gradient and deep neural network. Beijing Hangkong Hangtian Daxue Xuebao/Journal of Beijing University of Aeronautics and Astronautics, 41(4), 751-756. http://doi.org/10.13700/j.bh.10015965.2014.0499

Pelicioni, L. C., Ribeiro, J. R., Devezas, T., Belderrain, M. C. N., \& Melo, F. C. L. de. (2018). Application of a bibliometric tool for studying space technology trends. Journal of Aerospace Technology and Management, 10. http://doi.org/10.5028/jatm.v10.830

Pellegrino, A., Caprara, A., Cambioni, S., Pacchi, D., Cerini, C., Cau, C., \& Carbone, D. (2015). 'Look app', a free IOS application for space events. International Astronautical Federation, 13, 10570-10575.

Peters, M., Godfrey, C. M., Khalil, H., McInerney, P., Parker, D., \& Soares, C. B. (2015). Guidance for conducting systematic scoping reviews. International Journal of Evidence-Based Healthcare, 13(3), 141-146. http://doi.org/10.1097/XEB.0000000000000050

Rodríguez-Sevillano, A. A., Barcala-Montejano, M. A., Tovar-Caro, E., \& López-Gallego, P. (2016). Two experiences of blended learning process on engineering education. International Journal of Online Engineering, 12(9), 61-68. http://doi.org/10.3991/ijoe.v12i09.6146

Salgado, M., Belderrain, M., \& Devezas, T. (2018). Space Propulsion: A survey study about current and future technologies. Journal of Aerospace Technical Management, 10(e1118), 1-23. http://doi.org/10.5028/jatm.v10.829

Schmidt, J. (n.d.). Biggest problem in aerospace and defense: Navigating digital turbulence. Retrieved 1 July 2018, from http://speednews.com/article/114829

Scott, H. (1990). Simulations 'picture' IR scenes. Aerospace America, 28(1), 20-23. Retrieved from http://adsabs.harvard.edu/abs/ 
1990AeAm...28...20S

Shamseer, L., Moher, D., Clarke, M., Ghersi, D., Liberati, A., Petticrew, M., ... Stewart, L. A. (2015). Preferred reporting items for systematic review and meta-analysis protocols (PRISMA-P) 2015: Elaboration and explanation. BMJ Research Methods and Reporting, 349(1), g7647g7647. http://doi.org/10.1136/bmj.g7647

Sievers Jr., F., Rangel, R. K., \& Neto, P. P. C. (2014). WebLab a laboratory controlled remote access by the Internet: A case study of a UAVunmanned aerial vehicle with mobile device. In Iberian Conference on Information Systems and Technologies, CISTI. IEEE Computer Society. http://doi.org/10.1109/CISTI.2014.6876995

Simo, P., Fernandez, V., Algaba, I., Salan, N., Enache, M., Albareda-Sambola, M., ... Rajadell, M. (2010). Video stream and teaching channels: quantitative analysis of the use of low-cost educational videos on the web. In Uzunboylu, H (Ed.), Innovation and Creativity in Education (Vol. 2, pp. 2937-2941). http://doi.org/10.1016/j.sbspro.2010.03.444

Sinclair, P. A. (2009). Network centralization with the Gil Schmidt power centrality index. Social Networks, 31(3), 214-219. http://doi.org/10.1016/j.socnet.2009.04.004

Spil, T., Pris, M., \& Kijl, B. (2017). Exploring the BIG Five of e-leadership by developing digital strategies with mobile, cloud, big data, social media, and the Internet of things. In 5th International Conference on Management, Leadership and Governance: ICMLG 2017 (pp. 408-418). Johannesburg, South Africa. Retrieved from https://research.utwente.nl/ en/publications/exploring-the-big-five-of-e-leadership-by-developingdigital-stra

Thomas, H. M., Morfill, G. E., Fortov, V. E., Ivlev, A. V, Molotkov, V. I., Lipaev, A. M., ... Krikalev, S. K. (2008). Complex plasma laboratory PK-3 Plus on the International Space Station. New Journal of Physics, 10(3), 033036. https://doi.org/10.1088/1367-2630/10/3/033036

Trafton, J. G., Cassimatis, N. L., Bugajska, M. D., Brock, D. P., Mintz, F. E., \& Schultz, A. C. (2005). Enabling effective human-robot interaction using perspective-taking in robots. IEEE Transactions on Systems, Man, and Cybernetics- Part A: Systems and Humans, 35(4), 460-470. https://doi.org/10.1109/tsmca.2005.850592

Vagdevi, P., \& Guruprasad, H. S. (2016). A study on cloud computing in aviation and aerospace. International Journal of Computer Science \& Engineering Technology (IJCSET), 6, 94-98. Retrieved from http://www.ijcset.com/issue.php?file=vol06issue03

Van Der Heiden, P., Pohl, C., Bin Mansor, S., \& Van Genderen, J. (2015). The role of education and training in absorptive capacity of international technology transfer in the aerospace sector. Progress in Aerospace Sciences, 76, 42-54. http://doi.org/10.1016/j.paerosci.2015.05.003 van Eck, N. J., \& Waltman, L. (2017). VOSviewer Manual. Leiden University, The Netherlands. http://doi.org/10.3402/jac.v8.30072 
Wang, F., \& Hannafin, M. J. (2005). Design-based research and technologyenhanced learning environments. ETR\&D-Educational Technology Research and Development, 53(4), 5-23. http://doi.org/10.1007/978-14020-9827-7

Wang, G., Gu, Q., Wu, J., \& Wang, M. (2015). The concept and architecture of mission system for next generation aircraft. 2015 IEEE/AIAA 34th Digital Avionics Systems Conference (DASC). https://doi.org/10.1109/dasc.2015.7311444

Wang, M., Birken, R., \& Shahini Shamsabadi, S. (2014). Framework and implementation of a continuous network-wide health monitoring system for roadways (Vol. 9063). San Diego, CA: SPIE. http://doi.org/10.1117/12.2047681

Wasserman, S., \& Faust, K. (1994). Social network analysis: Methods and applications. Cambridge University Press, 1, 116. http://doi.org/10.1525/ae.1997.24.1.219

Winker, D. M., Couch, R. H., \& Mccormick, M. P. (1996). An overview of LITE: NASA's lidar in-space technology experiment. Proceedings of the IEEE, 84(2), 164-180. http://doi.org/10.1109/5.482227

Wiseman, Y. (2016). Unlimited and protected memory for flight data recorders. Aircraft Engineering and Aerospace Technology, 88(6), 866872. http://doi.org/10.1108/AEAT-06-2015-0152

World Economic Forum. (2017). Digital transformation initiative aviation, travel and tourism industry. Retrieved from http://reports.weforum.org/ digital-transformation/wp-content/blogs.dir/94/mp/files/pages/files/wefdti-aviation-travel-and-tourism-white-paper.pdf

Xia, L., \& Zhong, B. (2018). A systematic review on teaching and learning robotics content knowledge in K-12. Computers \& Education, 127, 267282. https://doi.org/10.1016/j.compedu.2018.09.007

Xu, D., Bil, C., \& Cai, G. (2013). A low cost CDF framework for aerospace engineering education based on cloud computing (pp. 560-567). Melbourne, VIC. http://doi.org/10.3233/978-1-61499-302-5-560

Yan, E., \& Ding, Y. (2012). Scholarly network similarities: How bibliographic coupling networks, citation networks, cocitation networks, topical networks, coauthorship networks, and coword networks relate to each other. Journal of the American Society for Information Science and Technology, 63(7), 1313-1326. https://doi.org/10.1002/asi.22680

Zawacki-Richter, O., \& Latchem, C. (2018). Exploring four decades of research in computers \& education. Computers \& Education, 122, 136152. https://doi.org/10.1016/j.compedu.2018.04.001

Zhang, G. W. (2015). Towards new heights of traffic to commemorate the 60th anniversary of Tsien Hsueshen homecoming. Journal of Transportation Systems Engineering and Information Technology, 15(4), 1-9. Retrieved from http://en.cnki.com.cn/Article_en/CJFDTotal-YSXT201504001.htm

Zhang, J., Yu, Q., Zheng, F., Long, C., Lu, Z., \& Duan, Z. (2015). Comparing keywords plus of WOS and author keywords: A case study of patient 
adherence research. Journal of the Association for Information Science and Technology, 67(4), 967-972. https://doi.org/10.1002/asi.23437

Zhang, Q.-R., Li, Y., Liu, J.-S., Chen, Y.-D., \& Chai, L.-H. (2017). A dynamic co-word network-related approach on the evolution of China's urbanization research. Scientometrics, 111(3), 1623-1642. https://doi.org/10.1007/s11192-017-2314-1

Zuppardi, G., \& Napolitano, L. G. (1987). Teaching aerodynamics using a microcomputer. Computers \& Education, 11(2), 73-84.

https://doi.org/10.1016/0360-1315(87)90002-9 


\section{Appendix}

Table A1

Design-based research of articles (1)

$\begin{array}{llllll}\begin{array}{l}\text { Author(s) } \\ \text { year }\end{array} & \begin{array}{l}\text { Digital } \\ \text { Tech. }\end{array} & \begin{array}{l}\text { Research Research } \\ \text { sample }\end{array} & \begin{array}{l}\text { Intervention } \\ \text { setting }\end{array} & \begin{array}{l}\text { Results } \\ \text { Type (DBR) }\end{array} & \begin{array}{l}\text { Iteration } \\ \text { (DBR) }\end{array} \\ \text { (DBR) }\end{array}$

Cifuentes-

Rodriguez

Fernandez

Castejon- simulator Underg. NA

Technological

intervention

Limas,

(testing Improved

motivation

NA

Alfonso-

environment)

Cendon

(2016)

Vo,

Trepanier Simulation Underg. Project based (2016)

learning

\section{Method}

/Strategy

(curriculum

unit)

improved Final

Simulation

Jordana, / Web 2.0:

Robert ePortfolio

(2015) (Google sites)

\section{PBL /}

laboratory session / Face-

to-face

\section{Strategy (curriculum unit)}

Active learning

Shankar,

Chung,

Husman,

Wells

MATLAB/ Underg.
Flight

(2015)

Zeng,

Zhang,

Huang,

Dong

(2014)

method/ hands- curriculum strategies and

actual

Strategy Improved

(method)

motivation

ON

performance

Systematic Strategy Improved

multi-hierarchy (method / skills/

MATLAB/ Graduate
Siumlink

educational

ON 


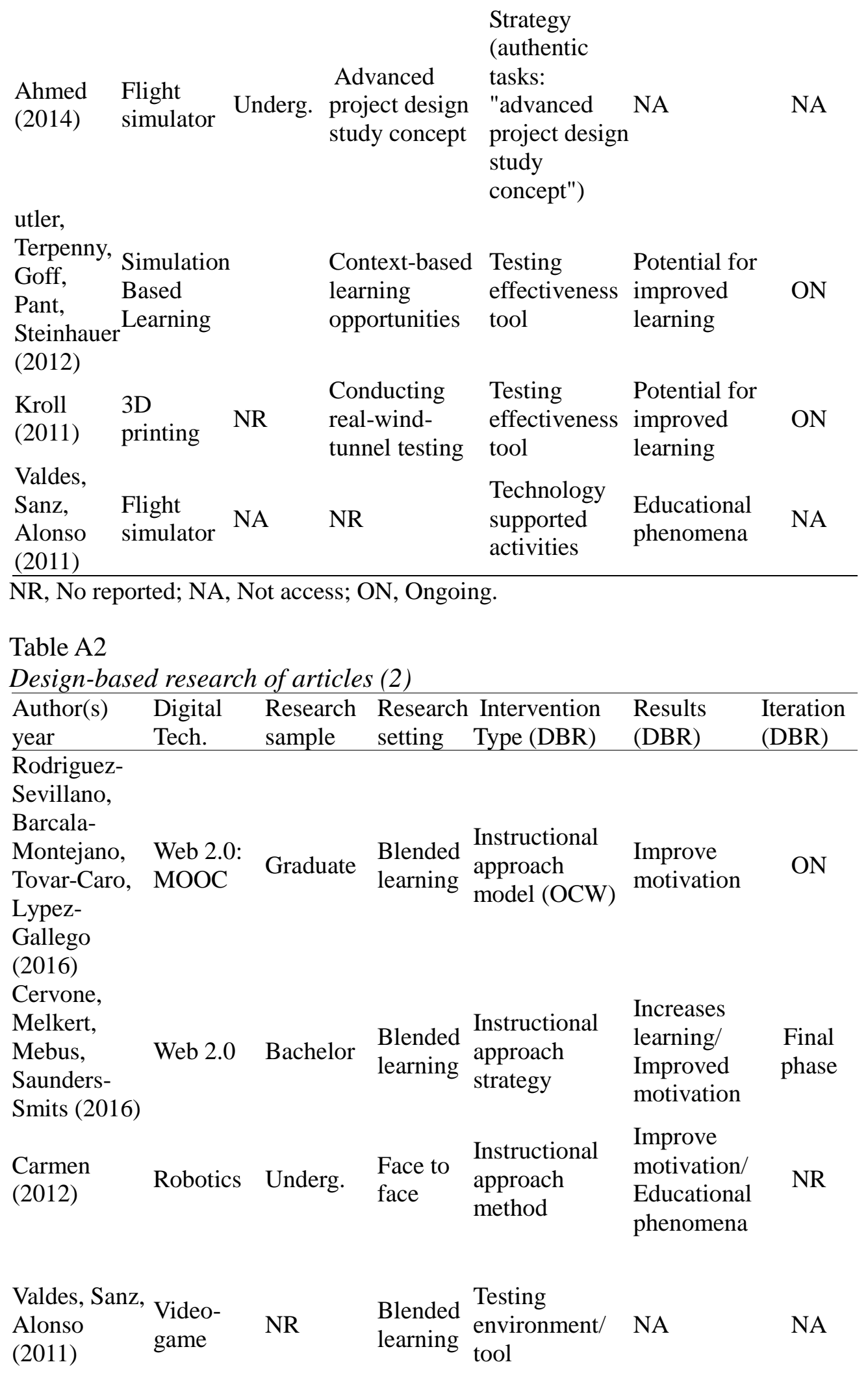




\begin{tabular}{|c|c|c|c|c|c|}
\hline Joshi (2004) & $\begin{array}{l}\text { MATLAB } \\
\text { computer } \\
\text { simulation Graduate } \\
\text { / Robotics }\end{array}$ & $\begin{array}{l}\text { Face to } \\
\text { face }\end{array}$ & $\begin{array}{l}\text { Strategy } \\
\text { (authentic } \\
\text { tasks: } \\
\text { simulation } \\
\text { project) }\end{array}$ & $\begin{array}{l}\text { Educational } \\
\text { phenomena / } \\
\text { Improved } \\
\text { attitude }\end{array}$ & $\begin{array}{l}\text { Final } \\
\text { Phase }\end{array}$ \\
\hline $\begin{array}{l}\text { Goldin, } \\
\text { Venneri, } \\
\text { Noor } \\
(1999)\end{array}$ & Simulation NA & NA & NA & NA & Pre stage \\
\hline $\begin{array}{l}\text { Boles, } \\
\text { Bernold, } \\
\text { Scott } \\
(1995)\end{array}$ & Robotics & $\begin{array}{l}\text { Face to } \\
\text { face }\end{array}$ & $\begin{array}{l}\text { Strategy } \\
\text { (authentic } \\
\text { tasks) }\end{array}$ & $\begin{array}{l}\text { Improve } \\
\text { attitude }\end{array}$ & NR \\
\hline
\end{tabular}

NR, No reported; NA, Not access, ON, Ongoing. 